\title{
Pactos de deuda sostenible: un mecanismo de reestructuración de cara a una crisis empresarial ${ }^{1}$
}

\author{
Sustainable debt covenants: a restructuring \\ mechanism in the face of a business crisis
}

\author{
Miguel BRECI RAMÍREZ ${ }^{2}$ \\ DANIEL MONCAYO SANTACRUZ ${ }^{3}$
}

\section{RESUMEN}

El Decreto 560 de 2020 trae dentro de sí unas figuras a las que él mismo denomina "Mecanismos de alivio financiero y reactivación empresarial" donde se encuentran instituciones como lo son la capitalización y la descarga de pasivos y, la figura que a través de esta investigación se procederá a analizar, los Pactos de Deuda Sostenible. Para esto haremos un análisis con figuras análogas que se encuentran en nuestro ordenamiento logrando así aproximarnos a su naturaleza jurídica para concluir con la identificación de los rasgos característicos que permitan distanciarse de sus semejantes. Por tal motivo, tomaremos los acuerdos que la Superintendencia Financiera de Colombia ha denominado como mecanismos de reestructuración del crédito, instituciones como lo son la Novación, las quitas de deudas y las Condonaciones. Mecanismos que la

1 Fecha de recepción: 14 de octubre de 2020. Fecha de aceptación: 9 de diciembre 2020 Para citar el artículo: Brecci M. y Moncayo D. "Pactos de deuda sostenible: un mecanismo de reestructuración de cara a una crisis empresarial". Revist@ E-Mercatoria, vol. 19, n. ${ }^{\circ}$ 2, julio-diciembre 2020.

DOI: https://doi.org/10.18601/16923960.v19n2.03

2 Estudiante 5 año de Derecho de la Universidad Externado de Colombia, integrante del seminario de Obligaciones Civiles y Comerciales (2018) de la Universidad Externado de Colombia, miembro Investigador del Semillero a cargo del Departamento de Derecho comercial (2019). Caracas, Venezuela. Correo-e: miguel.breci@est.uexternado.edu.co

3 Estudiante 5 año de Derecho de la Universidad Externado de Colombia, integrante del seminario de Obligaciones Civiles y Comerciales (2018) de la Universidad Externado de Colombia.San Juan de Pasto, Colombia. Correo-e: daniel.moncayo@est.uexternado.edu.co 
misma entidad ha catalogado y reconocido como herramientas que permiten superar las dificultades de los deudores para lograr la atención regular de sus obligaciones, permitiendo así la realización de un examen mucho más preciso con atención a los Pactos de Deuda Sostenible como se verá a continuación.

Palabras clave: Pactos de Deuda Sostenible, mecanismos de reestructuración del crédito, mecanismos de recuperación empresarial, medidas transitorias especiales, crisis empresarial, emergencia social y ecológica.

\section{ABSTRACT}

The Decree n. 560 of 2020 brings some figures that it calls "Mechanisms of financial relief and business reactivation", in which it can be found institutions such as capitalization, discharge of liabilities and, the figure subject of study, the sustainable debt pacts. In the present article the reader will encounter an in-depth study, in which it is obtained as a result the determination of the legal nature, the concept, the function and advantages intended to be established with the inclusion of the figure in the aforementioned Decree.

Key words: Mechanisms of financial relief and business reactivation, debt pacts.

\section{APROXIMACIONES A LOS MECANISMOS DE REESTRUCTURACIÓN DEL CRÉDITO EN EL ORDENAMIENTO JURÍDICO COLOMBIANO}

En el ordenamiento jurídico colombiano han surgido diferentes figuras mediante las cuales acreedores y deudores acuerdan aligerar las cargas del deudor, facilitando el cumplimiento de sus obligaciones, redefiniendo así sus nuevos términos y condiciones entre ambas partes. La aplicación de estas herramientas está marcada por la manifestación del principio de la autonomía privada de las partes y la libertad contractual, teniendo presente que es un acuerdo que se realiza de cara a la realidad de la situación en la que se encuentra el deudor al momento de su celebración. Los convenios que se evidencian en la práctica son en ciertos eventos las reestructuraciones del plazo, las reducciones en las tasas, las novaciones, las quitas con mayor frecuencia y, la figura que nos ocupa en el desarrollo de este trabajo, los Pactos de Deuda Sostenible.

Una vez mencionados los mecanismos anteriores es importante comprender que la utilidad de estas figuras se deriva de la incapacidad de pagar del deudor en las condiciones inicialmente pactadas, en tanto son mecanismos que reestructuran el crédito y recomponen la capacidad de pago del deudor. 
Se incluyen en esta categoría en virtud de que estas figuras generalmente tienen por fin modificar los plazos estipulados para hacer efectivos los pagos, evitando que se acumule el pasivo de la empresa en períodos de corto plazo y así reescalonar la deuda para poder pagarse de una forma más cómoda a largo plazo.

En su Circular Externa 016 expedida por la Superintendencia Financiera de Colombia con fecha de 2 de julio de 2019 esta corporación señala que los mecanismos de reestructuración de crédito se entienden como: "cualquier mecanismo excepcional, instrumentado mediante la celebración y/o ejecución de cualquier negocio jurídico, que tenga por objeto modificar las condiciones originalmente pactadas con el fin de permitirle al deudor la atención adecuada de su obligación ante el real deterioro de su capacidad de pago" ${ }^{\prime 4}$. Adicionalmente, la Superintendencia de Sociedades también señaló, en oficio 220-246341 del 15 de diciembre de 2016, que estos mecanismos pueden versar sobre temas accesorios a la obligación principal, tales como "capital, intereses de plazo, moratorios, comisiones, gastos, indemnizaciones, aspectos convencionales, sanciones, tasas de interés, clausula penal, indemnizaciones, daño emergente, lucro cesante etc." ${ }^{\text {"5 }}$. Así, aunque se cuente con cierta información de los mecanismos de reestructuración del crédito, no se conoce con claridad cuáles son los efectos y las características particulares que entre cada uno de ellos pueda existir.

Resulta entonces importante esclarecer las diferencias entre las figuras anteriores por la incorporación de los Pactos de Deuda Sostenible en el reciente Decreto 560 de 2020, el cual fue expedido por el Gobierno Nacional con la intención de aumentar las herramientas con las que cuentan las empresas que a raíz de la crisis por la Covid-19 se vean inmersas en un proceso de insolvencia. Dicho Decreto regula un régimen de insolvencia especial con la finalidad de "mitigar la extensión de los efectos sobre las empresas afectadas por las causas que motivaron la declaratoria del Estado de Emergencia Económica, Social y Ecológica de que trata el Decreto 417 del 17 de marzo de 2020, y la recuperación y conservación de la empresa como unidad de explotación económica y fuente generadora de empleo, a través de los mecanismos de salvamento y recuperación aquí previstos", razón por la cual dispone de estos pactos para coadyuvar en la reactivación de las empresas que se hayan visto afectadas por la pandemia.

Ahora bien, debido al poco desarrollo que se dio a dichos pactos y al no tener mayor claridad sobre las posibles distinciones existentes entre los mecanismos de reestructuración, podríamos encontrarnos en un evento en el cual se esté ante el desarrollo de una figura totalmente nueva o que se pretenda simplemente regular su aplicación de una manera más detallada. Por

4 Superintendencia de Industria y Comercio de Colombia. Circular Externa n. ${ }^{\circ} 016$ de 2 julio de 2019

5 Superintendencia de Sociedades de Colombia. oficio 220-246341 del 15 de diciembre de 2016 
estos motivos es que cobra relevancia analizar la figura en el sentido de que podamos entender el funcionamiento de estas disposiciones y así aplicarlas en la forma prevista esperando que cumplan con su finalidad.

Hay que resaltar que la Superintendencia Financiera de Colombia en su Circular Externa 016 de 2019 menciona que, "las reestructuraciones no pueden convertirse en una práctica generalizada para regularizar el comportamiento de la cartera de créditos y las mismas no podrán fundamentarse en el uso excesivo de periodos de gracia"6. Lo que indica que la institución no prioriza las ventajas que estos mecanismos acarrean para el deudor, sino que los asimila como una afectación única al acreedor por lo que no promueve su uso frecuente.

La incorporación de estas figuras en nuestro ordenamiento no prevén una vía de incumplimiento a la que el deudor pueda acudir deliberadamente para eludir el pago de una obligación vigente. Las obligaciones están hechas para cumplirse, por lo cual todo comportamiento del deudor debe estar orientado a respetar la legitima acreencia. No obstante, estas herramientas fueron ideadas para facilitar el proceso de recuperación de una empresa que encuentre comprometida su capacidad económica, siempre y cuando se procure satisfacer el derecho del acreedor a ser pagado.

Es así como, de invocarse uno de estos mecanismos en situaciones normales y si dentro de la validación realizada por el juez competente no se evidencian los principios de la Buena Fe, la Transparencia y la Claridad del deudor, podría devenir en una situación de abuso del derecho, donde, bajo los entendidos del doctor Valencia Zea, "Los derechos subjetivos de los particulares, tanto en su existencia como en su ejercicio, obedecen a una orientación determinada y de esos derechos se abusa cuando existiendo el deber de ejercerlos no se ejercen, o se ejercen en sentido opuesto a su propio destino o contenido"7 quedando este comprendido dentro de un acuerdo privado con las consecuencias que le son inherentes.

\section{LA NOVACIÓN Y LAS QUITAS DE DEUDAS}

En virtud de su antigüedad y desarrollo la novación ha de ser el primer convenio objeto de estudio en atención al análisis que debemos realizar. La novación está regulada en el código civil y este la ha entendido según su artículo 1687 como la sustitución de una obligación por otra nueva, extinguiendo la anterior. El Maestro Fernando Hinestrosa definía la figura de la siguiente manera: "La novación es la sustitución de una obligación primitiva que queda extinguida, por una posterior surgida por acuerdo entre las partes; estas, creando una nueva

6 Superintendencia de Industria y Comercio de Colombia. Circular Externa n. ${ }^{\circ} 016$ de 2 julio de 2019.

7 Valencia, Arturo, 1998. Derecho Civil de las Obligaciones, t. III, Bogotá, Edit. Temis, p. 304 . 
relación obligatoria, extinguen la precedente (art. 1687) su función es, pues mixta, extingue a la que crea o constituye"8.

El Código Civil establece en su artículo 1690 para esta modalidad de extinción de las obligaciones tres hipótesis distintas en las que puede darse, entre las cuales encontramos: "I) Sustituyéndose una nueva obligación a otra, sin que intervenga nuevo acreedor o deudor, II) Contrayendo el deudor una nueva obligación respecto de un tercero, y declarándole en consecuencia libre de la obligación primitiva el primer acreedor y, III) Sustituyéndose un nuevo deudor al antiguo, que en consecuencia queda libre." ${ }^{\prime 9}$ Permitiendo entender que la realización de una novación supondría un cambio en el sujeto, objeto o en la prestación debida.

Es importante aclarar en este punto que, para la aplicación de esta figura, siempre debemos estar frente a los principios de autonomía privada y libertad de la voluntad. Dado que, al tener estas figuras un carácter contractual, siempre va a ser requerido el consentimiento de cada una de las partes y su aceptación. Con lo anterior se quiere decir que, si no hay aceptación por ambas partes, sin importar quién realice la propuesta, la obligación inicial quedara inmutada, totalmente en consonancia al pacto inicialmente acordado sin afectarse en lo más mínimo.

Al tratarse de un negocio jurídico se debe contar con todos los presupuestos de validez que se exigen dentro del artículo 1502 al señalar que: "Para que una persona se obligue a otra por un acto o declaración de voluntad, es necesario: 10.) que sea legalmente capaz. 20.) que consienta en dicho acto o declaración y su consentimiento no adolezca de vicio. 3o.) que recaiga sobre un objeto lícito y 40.) que tenga una causa lícita"10. Igualmente, el código cuando establece la novación señala que "para que sea válida es necesario que tanto la obligación primitiva como el contrato de novación, sean válidos, a lo menos naturalmente". Por último, para celebrar una novación es importante que se evidencie que ambas partes efectivamente cuenten con un animus novandi que no es cosa diferente a aquel propósito o intención concreta de acreedor y deudor para extinguir la primera relación y crear una nueva.

Es menester señalar que, como mecanismo de reestructuración de las obligaciones, esta figura ha perdido importancia en la práctica y esto sucede porque al celebrarse este negocio jurídico no se solía incluir las garantías que acompañan la obligación inicial dejando desprotegido al acreedor frente a la segunda obligación. De la misma manera sucedía con los intereses que tenía a su favor el acreedor puesto que, al ser una obligación nueva, no podía apelar a las garantías o los intereses que se habían constituido en la obligación ya extinguida. Fue así como empezaron a cobrar relevancia otras figuras del

8 Hinestrosa, Fernando. 2007, Tratado de las Obligaciones, Concepto, Estructura, Vicisitudes, Bogotá D.C. Universidad Externado de Colombia.

9 Código Civil Colombiano, artículo 1690

10 Código Civil Colombiano, artículo 1502 
ordenamiento jurídico que no incluyen la regla legal donde se altera sujeto, objeto u obligación, que ha ocasionado que pierda su atractivo.

Ahora bien, para referirnos a las quitas de deuda tenemos que señalar inicialmente que, aunque se ha usado en la práctica y se ve aplicada con frecuencia dentro del área financiera, la realidad es que carece de una regulación integral dado que no encuentra un desarrollo extenso en la legislación colombiana. Dicho lo anterior, algunas entidades financieras internacionales han dado algunas definiciones sobre las quitas, por ejemplo, el BBVA las ha definido como "acuerdos entre deudor y acreedores que intentan solucionar situaciones de impago. El acreedor renuncia al cobro de una parte de esa deuda a cambio de asegurarse el cobro del resto" ${ }^{\prime \prime}$, lo que permite afirmar que estamos frente a un convenio en el cual el deudor se compromete a pagar una parte de la deuda mientras que el acreedor renuncia a su derecho para perseguir la parte restante de la obligación reestructurada.

Nuestra ley de insolvencia, la ley 1116 de 2006 menciona las quitas en su artículo 33 dentro del cual se establecen las mayorías especiales para que se pueda dar una rebaja al capital. Dentro de este artículo vemos esa función de disminuir el capital que se va a pagar en dos vías distintas que son las que se mencionan en su numeral $1^{\circ}$ y $2^{\circ}$ como trataremos más a fondo en el siguiente acápite. Sin embargo, estas dos vías para pactar una quita de deuda se presentan, en el primer caso, bajo el supuesto de la existencia de una mayoría de acreedores que aprueben su imposición en el acuerdo de reorganización cuando en palabras del artículo su celebración implique que "el pago de las acreencias objeto de reorganización sea inferior al valor del capital de las mismas" ${ }^{\prime \prime 2}$. Por otro lado, el numeral segundo alude a la posibilidad de celebrar una quita con un acreedor apartado del resto, pero en este caso su incorporación en los acuerdos de reorganización será mediante una cláusula contractual.

Es así como contando con el voto de la mayoría de los acreedores haría que el acuerdo de reorganización se realice bajo la premisa de que se ha renunciado en conjunto al cobro de una parte de la acreencia. Entonces, mientras el acuerdo se estructura de manera tal que se imponga la disminución del pago en virtud de la renuncia frente a la totalidad de los acreedores, la celebración individual de una quita se incorporará al acuerdo de reorganización como una cláusula considerada frente a la acreencia en particular.

Las particularidades que hemos denotado en ambas figuras resultan oportunas para identificar las diferencias que entre ellas existen. Por un lado, sobre la novación hay que recordar que el ordenamiento jurídico la entiende como la extinción de una obligación mediante la creación de un nueva. Lo

11 ¿Qué son las quitas de deuda?, BBVA. Actualización 13 de Junio de 2018. https://www. bbva.com/es/que-son-las-quitas-de-deudas/

12 Ley 1116 de 2006, artículo 33 
que quiere decir que, cuando se acude a este mecanismo buscando aligerar la carga que recae sobre el deudor, se deberá precisar qué estipulaciones sucederán al nuevo convenio. Esto en razón de que, al haberse extinguido la obligación anterior, de no incluirse las garantías o los intereses, el acreedor podría verse afectado en mayor medida a la que estaba dispuesto renunciando a perseguir una parte de la obligación. En esto difieren las quitas de deuda, puesto que al no celebrarse nuevamente el negocio jurídico se reduce el monto de la obligación por cumplir. En este evento dependerá de quiénes aprueben o quieran acogerse a este mecanismo de manera individual dado que, como ya se advirtió, su inclusión en los acuerdos de reorganización podrá ser de manera accesoria o impositiva sin que signifique la extinción de un negocio jurídico por el surgimiento de uno nuevo. Es por esta razón que no habrá que preocuparse por dejar fuera del acuerdo de reorganización las medidas de protección con las que cuenta el acreedor ni sus intereses.

Son estas las razones por las cuales la novación en Colombia ha perdido importancia como mecanismo de reestructuración del crédito y ha incrementado el uso de otros mecanismos como las quitas de deudas cobrando mayor relevancia en el marco de una situación de insolvencia al no significar un perjuicio adicional al acreedor frente al riesgo de no incluir elementos que garanticen el cumplimiento de la obligación. Sin embargo, el uso de estas herramientas ha tomado tanta importancia dentro de los procesos concursales que han surgido nuevas figuras en nuestra legislación con el mismo fin. Un ejemplo de lo anterior son los Pactos de Deuda Sostenible, mecanismo previsto para la recuperación y la superación de la crisis empresarial por la situación económica que atraviesa el país a causa de la Covid-19.

\section{CONCEPTO DE PACTO DE DEUDA SOSTENIBLE A PARTIR DEL DECRETO 560 DE 2020}

Con la intención de mitigar las consecuencias provenientes de la pandemia, la Presidencia de la Republica expidió el Decreto 560 del 15 de abril de 2020 incorporando algunas medidas transitorias para los procesos de insolvencia que surgieran con ocasión del Estado de Emergencia Económica, Social y Ecológica que atraviesa Colombia. En el artículo 4, el Decreto procura facilitar los procesos de pago de los deudores frente a las obligaciones pendientes con las distintas clases de acreedores señalando vías alternas para su procedencia. Una de las herramientas que se incorpora como "mecanismo de alivio financiero y reactivación empresarial" es el pacto de deuda sostenible, pacto que permite indagar posibles soluciones especiales con las cuales puedan establecerse nuevas condiciones de cumplimiento para las obligaciones que existan al momento de la entrada en insolvencia del deudor.

La figura que trae la norma tiene por finalidad reducir el período en el que se realizan los pagos a los acreedores financieros mediante una restructuración 
de la obligación. Para que se aplique la reestructuración se debe contar con una mayoría especial la cual se estipula que será del $60 \%$ de los acreedores financieros que se encuentren inmersos en ese proceso de reorganización y que acepten la celebración del pacto. El artículo termina por señalar que, una vez realizado el acuerdo, la obligación solo se entenderá cumplida al momento en que el deudor emita los títulos correspondientes que contengan los términos que se hayan convenido.

El texto normativo como se mencionó expresa el fin y ciertos presupuestos para la procedencia de la figura que resulta importante abarcar en esta parte del trabajo. Se infiere de la norma que frente a las obligaciones contraídas con los acreedores financieros se abre la posibilidad de reformular la obligación de manera que se ponga en consideración la modificación de los plazos de pago, siendo convenido por ambas partes contractuales. Lo ideal será siempre recibir la totalidad del monto adeudado, sin embargo, los acreedores deberán tener en cuenta que, dada la situación de insolvencia de muchas empresas y la razón que motivó el Decreto, que es la crisis económica que se avizora, las probabilidades de un impago total del crédito son mucho más altas. Esto quiere decir que el "reperfilamiento" puede suponer la inclusión de un acuerdo en el que, mediada la autonomía privada y la libertad contractual, se incluya también una reducción del pasivo a pagar atendiendo a la capacidad de pago del deudor, condonando el pasivo restante flexibilizando su cumplimiento en el tiempo.

Como se mencionó en su momento, los principios de la autonomía privada y la libertad contractual son los principios rectores de los acuerdos de reorganización. Lo que quiere decir que, en virtud de estos dos principios, no habría impedimentos para que este mecanismo sea usado por los diferentes acreedores, incluso dentro de un acuerdo privado. Sin embargo, en razón de su carácter urgente se consideró principalmente para los acreedores financieros puesto que estos son una pieza muy importante en la recuperación de las empresas.

Una vez establecida la flexibilidad sobre los plazos de pago y la posibilidad de reducir el pasivo a pagar por el deudor invocando los principios mencionados, como las funciones primordiales de la figura, podemos afirmar que cumple con los presupuestos para ser considerada como un mecanismo de reestructuración del crédito. Ahora, recordando cómo se han entendido estos mecanismos en nuestra legislación veremos que se trata de la celebración de un negocio jurídico en particular. La Superintendencia Financiera de Colombia en su Circular Básica Contable y Financiera n. ${ }^{\circ} 100$ de 1995) en su numeral 12 del capítulo II señala qué debemos entender por reestructuración del crédito cuando señala que, "se entenderá como crédito o contrato reestructurado aquél respecto 
del cual se ba celebrado un negocio jurídico de cualquier clase que tenga como objeto o efecto modificar cualquiera de las condiciones originalmente pactadas, en beneficio del deudor ${ }^{\prime \prime 13}$.

Es importante señalar que la circular de la Superintendencia Financiera de Colombia sugiere que la modificación a las condiciones o los efectos de las obligaciones se entenderán incorporadas a través de la celebración de un negocio jurídico que cuente con esa intención. En ese sentido no sobra repasar qué ha entendido la doctrina por negocio jurídico para así poder concluir que los Pactos de Deuda Sostenible hacen parte de esta categoría.

Por negocio jurídico, grandes doctrinantes como lo es el maestro Fernando Hinestrosa lo han definido a partir de la postura voluntarista que tiene su origen en la doctrina pandectistica alemana por el reconocimiento de la voluntad en el derecho positivo, como "manifestaciones de la voluntad del hombre con miras a producir un efecto jurídico, es decir con intención de engendrar, modificar o extinguir derechos"14, para lo cual también ha expresado que dentro del derecho privado, "Ha sido empleado siempre para señalar la conducta particular de disposición de los propios intereses en relaciones del comercio jurídico"15. A su vez, Valencia Zea también lo define a partir de la doctrina alemana al establecer que, "por tal se entiende aquel becho jurídico que contiene una o varias declaraciones de voluntad de los particulares que, por si o unidos con otros requisitos, persiguen un determinado efecto jurídico"16.

Entonces, a partir de las funciones modificatorias del convenio inicialmente celebrado por las partes a través de la incorporación de un pacto de deuda sostenible dentro de los acuerdos de reorganización y por su esencia dispositiva sobre los intereses de los particulares es que se puede reconocer su naturaleza de negocio jurídico indicando así que es igualmente exigible su cumplimiento ante el juez del concurso.

Son las razones aquí expresadas las cuales nos obligan a realizar un análisis incluso más exhaustivo frente a la figura, dado que, en virtud de los principios mencionados se ha dificultado la diferenciación entre sus funciones. Debido a que se podría encontrar mayor similitud con las quitas de deuda, se procederá a analizarse el símil de ambas figuras para así dirimir la discusión que se ha suscitado y permitir el uso pleno de ambas dentro de los acuerdos de reorganización, ajustándose a las necesidades de las partes.

13 Superintendencia Financiera de Colombia. Circular Básica Contable y Financiera n. ${ }^{\circ}$ 100 de 1995.

14 Hinestrosa, Fernando. 2007, Tratado de las Obligaciones, Concepto, Estructura, Vicisitudes, Bogotá D.C. Universidad Externado de Colombia.

15 Ibidem.

16 Valencia, Arturo, 1998. Derecho Civil, Parte General y Personas. Tomo I, Bogotá, Edit. Temis, p. 452. 


\section{EFECTOS CONTABLES DE LOS PACTOS DE DEUDA SOSTENIBLE COMO CONDONACIÓN PARCIAL Y LAS QUITAS DE DEUDAS COMO RENUNCIA PARA PERSEGUIR (PACTUM DE NON PETENDO)}

Corresponde ahora centrar el análisis en la figura que se incorpora en el Decreto 560 de 2020, los Pactos de Deuda Sostenible como mecanismo de reestructuración del crédito y los efectos que surgen al ser tratados como tales. Sobre estos pactos habría que decir que el Decreto trae una descripción que la presenta como un "mecanismo de reestructuración de crédito" que, a través de la modificación de la obligación mediante la aprobación conjunta de unos acreedores calificados vinculados al proceso de insolvencia, permite la flexibilización en los plazos para pagar la deuda existente.

Se entiende como un mecanismo de reestructuración de crédito dado que su fin apunta a la reactivación de la empresa mediante el reperfilamiento o la reestructuración de las obligaciones existentes. Así lo señala el artículo 4 de este Decreto, cuando reza que la funcionalidad de esta figura será respecto de incluir disposiciones que flexibilicen "los plazos de pago de las obligaciones y pagos a los acreedores de distintas clases de forma simultánea o sucesiva." 17

Por flexibilización de pagos debemos entender como aquel alivio que se le otorga al deudor sobre la exigibilidad de las obligaciones en el tiempo que permita, al momento de realizar el reperfilamiento de la deuda, contemplar una reducción del término para pagar lo debido. Lo anterior quiere decir que el pago de la deuda no se regirá mediante un cronograma de pago que someta al deudor a cumplir con una periodicidad estricta, sino que se pactará un límite de tiempo dentro del cual se deberá cumplir con la totalidad del monto acordado, estableciendo los parámetros en los cuales se irá aportando a esa deuda, sin exceder el límite de tiempo estipulado. Entretanto que, lo que nos indica el artículo respecto a la flexibilización de pago de los acreedores de manera simultánea o sucesiva, se debe entender en consonancia con lo que hemos señalado y que trataremos a fondo más adelante respecto de la importancia que tienen los acreedores financieros en este proceso de reorganización y la política proacreedor que tiene incluida este Decreto.

Cuando se habla sobre la flexibilización de los pagos a los acreedores de forma simultánea o sucesiva se quiere decir que, de celebrarse un Pacto de Deuda Sostenible con los acreedores financieros este se entienda como una facilidad para la realización pago, permitiendo a través del rescalonamiento de la deuda en el tiempo fraccionándola en sumas de menor cuantía para que la empresa pueda contar con un capital base para continuar con la ejecución de sus actividades e ir pagándose en su totalidad la deuda existente con dichos acreedores. También hay que tener presente que podría incluirse 
una reducción del pasivo a pagar que signifique un pago no de manera instantánea, pero sí de forma más expedita. Así dependiendo del capital de la empresa podría, dada la situación, pagarse a un conjunto de acreedores o permitirse mediante el reescalonamiento que se vayan pagando las deudas que más dificultan la recuperación de la empresa mientras continúe con su funcionamiento. Un ejemplo de lo anterior es que se acepte en los Pactos de Deuda Sostenible que se pague en primer lugar a las deudas de menor importe en razón de su cuantía para luego pagar de forma reescalonada las más complejas.

En vista de lo anterior, es importante señalar que nos encontramos frente a una herramienta de redefinición de la obligación que en principio está dirigida a aminorar la carga del deudor frente a los términos que se pactaron para realizar el pago. Haciendo la aclaración de que podría en virtud de la autonomía privada y la libertad contractual pactarse también la reducción del pasivo que se adeuda y los demás aspectos que se mencionaban al inicio de este capítulo.

A esto parecería apuntar el Gobierno Nacional en tanto que serán las partes las protagonistas en la realización del acuerdo sin la intervención de terceros. Por cuanto son ellas las que definen, de manera conjunta, cuáles serán las vías de cumplimiento que se acomoden a la realidad en que se encuentra el deudor y que el acreedor esté dispuesto a aceptar, haciendo bastante atractiva la figura frente a la situación económica que atraviesa el país.

Ahora bien, al aceptar que los Pactos de Deuda Sostenible son mecanismos de reestructuración del crédito y estos a su vez permitir plantear la posibilidad de incluir en el pacto la reducción del pasivo que se va a pagar, resulta importante aludir a las condonaciones y a las renuncias para perseguir derechos patrimoniales. Lo anterior, dado que podríamos encontrarnos, a lo largo del reperfilamiento de una obligación, frente al cese de pago de una parte de la deuda donde tendría distintos efectos de tratarse de un perdón o de una renuncia.

Sobre las condonaciones o remisiones tendremos que señalar que son el perdón oficial que le otorga un acreedor a un deudor y que este puede ser total o parcial. En nuestro código civil se encuentra enunciada esta institución, en su artículo 1625, reconociéndola como uno de los modos de extinción de las obligaciones. Asimismo, sobre su alcance la profesora de derecho Marcela Castro Ruiz ha señalado que, "si la remisión es total se extingue todas las garantías y accesorios, como los intereses y la bipoteca. Si es parcial sólo extingue la deuda basta la concurrencia de lo condonado, pero no extingue los accesorios" ${ }^{\prime \prime 18}$. Lo que quiere decir que tanto el perdón sobre la totalidad de la obligación como el perdón parcial son formas de extinguir la obligación, con la diferencia de que cuando 
de una condonación parcial se trate la obligación se extinguirá sobre la suma que fue condonada.

Dado por su similitud con las remisiones, hablar de las renuncias para perseguir el pago parcial de las obligaciones que se tienen con los acreedores resulta idóneo para establecer los efectos que conlleva su aquiescencia. Pero ¿qué se entiende por renuncia para perseguir el pago de una parte de la obligación? La renuncia se ha entendido como un acto unilateral proveniente de un acreedor que desiste de reclamar un derecho patrimonial o perseguir una acreencia. De esta manera cuando nos referimos a la renuncia como una forma de prescindir al cobro de las obligaciones, se asemeja a la figura proveniente del derecho romano denominada pactum de non petendo. Puesto que esta figura era entendida por los romanos como una constancia en la cual el acreedor expresaba su renuncia a perseguir la deuda que se tenía de manera total o parcial y si luego se arrepentía de haber decidido no exigir, el deudor encontraba seguridad en ella al poder oponerla ante el juez como una excepción sin que signifique la extinción de la obligación.

Se entiende entonces que la renuncia se da sobre la acción con la que se cuenta para perseguir el crédito mientras que la condonación es el perdón oficial que se da sobre determinada suma. Así podríamos ver que en el evento en que se pague más allá de lo que se había renunciado se entenderá como un pago de lo debido, por cuanto la obligación en teoría sigue vigente, solo que esta ya no es exigible, por lo tanto, su pago se entendería como el pago de una obligación natural. Lo anterior en contraposición de lo que sucedería con una condonación porque esta sí extingue la obligación. Razón por la cual, de darse un pago que involucre la parte que ha sido condonada, se estaría en presencia de un pago de lo no debido, siendo así exigible su devolución.

Otra diferencia plausible entre la condonación y la renuncia la encontramos dentro del sector financiero puesto que las características inherentes de ambas instituciones permiten entender mejor los efectos contables de los diferentes mecanismos de reestructuración del crédito en el historial crediticio. Existen investigaciones que permiten establecer que la quita, como mecanismo de reestructuración, conlleva efectos negativos que pueden afectar la calificación de una empresa, pudiéndose equiparar a una renuncia para perseguir una parcialidad del monto adeudado como se estudiará más adelante. En tanto que, de expresarse como una condonación la reducción del pasivo que se adeuda en los Pactos de Deuda Sostenible no tendría el mismo inconveniente frente a la petición de un crédito en el futuro debiendo constar de forma expresa dentro del negocio jurídico.

Respecto del efecto contable de las quitas de deudas, la revista de economía "el economista" de México se ha pronunciado sobre ellas y ha dicho que: "si acepta una reestructuración, donde se le ofrezca que le bagan una "quita", su institución financiera va a aceptar dejar de cobrar parte de su deuda. Pareciera ser la opción más ventajosa, sin embargo, tiene que saber que traerá consecuencias negativas para su 
bistorial crediticio y su capacidad de acceder a un nuevo financiamiento"19. Se evidencian entonces las consecuencias que acompañan a la celebración de una quita respecto del historial crediticio de una empresa y que a todas luces resulta perjudicial para su recuperación.

En el mismo sentido, la entidad mexicana denominada Comisión Nacional para la Protección y Defensa de los Usuarios Financieros ha mencionado que es posible realizar una reestructuración de deuda manteniendo una calificación positiva en el historial crediticio de la empresa. Mientras que, sobre las quitas, el sitio de noticias de negocios y tecnología Business Insider ha dicho que su uso "podría afectar la posibilidad de adquirir otro préstamo a futuro, pues al tratarse de un daño para la institución, como consecuencia deja una mala nota en el bistorial crediticio basta por 6 años ${ }^{120}$ esto dentro de la legislación mexicana. Es así como cobra relevancia la afirmación sobre la negativa por la celebración de una quita en el historial crediticio de la sociedad al igual que la idea de que no toda reestructuración debe interpretarse bajo el mismo entendido.

En nuestro ordenamiento jurídico podemos llegar a la misma conclusión. Dentro de su circular básica, contable y financiera la Superintendencia Financiera de Colombia ha señalado en Circular Externa 016 de 2019, que "para la adecuada reestructuración de los créditos, la entidad debe contar, al menos, con procedimientos que le permitan: C. Calificar los créditos reestructurados de conformidad con las instrucciones del presente Capítulo y sus Anexos" ${ }^{\prime 21}$. Lo que implica que nuestra legislación también califica el riesgo crediticio de quien acude a un mecanismo de reestructuración o a una quita de deuda, afectando a las empresas dificultando la posibilidad de acceder a un préstamo durante el proceso de reorganización para su recuperación e igualmente después de este siendo considerablemente perjudicial.

El mismo Decreto 560 pareciera hacer alusión a la importancia del otorgamiento de crédito toda vez que en su artículo 5 denominado "estímulos a la financiación del deudor durante la negociación de un acuerdo de reorganización ${ }^{\prime \prime 2}$ indica que se deberá incentivar a las entidades financieras a brindar el apoyo financiero respectivo porque es a través de estas que se podrá lograr el objetivo de reactivar el sector económico. Igualmente establece que los préstamos que se puedan otorgar en el marco de un proceso de reorganización tendrán la

19 Qué debe saber si va a reestructurar su deuda. El Economista. 24 de junio de 2018. https:// www.eleconomista.com.mx/finanzaspersonales/Que-debe-saber-si-va-a-reestructurarsu-deuda-20180624-0059.html

20 Consolidación, reestructuración y quita ${ }_{i}$ estas son las tres formas que los bancos pueden ofrecerte para negociar tu deuda, te decimos las diferencias. Business Insider Mexico. 3 de junio de 2020. https://businessinsider.mx/consolidacion-reestructuracion-y-quitatres-formas-que-los-bancos-pueden-ofrecerte-para-negociar-deudas/

21 Superintendencia de Industria y Comercio de Colombia. Circular Externa n. ${ }^{\circ} 016$ de 2 julio de 2019

22 Decreto 560 de 2020, artículo 5 
preferencia establecida dentro del artículo 71 de la ley 1116 de 2006 al pretender que serán pagados como gastos de administración, sin requerir para su celebración la autorización del juez del concurso.

Habiendo concluido que los créditos y su otorgamiento son el fundamento de los procesos de insolvencia y la recuperación empresarial, es que observamos las consecuencias sobre el historial crediticio de los deudores con mayor rigurosidad, toda vez que la financiación que realizan las entidades financieras juegan un papel de vital importancia en esta clase de procesos y en nuestra economía como la base del sistema de insolvencia.

Respecto a la intención motivadora del Decreto en que se financien a las empresas que se encuentren en una situación de insolvencia y teniendo presente la inclusión de los Pactos de Deuda sostenible en la norma, sería ilógico afirmar que su celebración conduzca a la afectación negativa del historial crediticio de quien acuda a estos pactos, como sucedería con las quitas. Igualmente se debe tener presente la esencia de la figura que, al ser incorporada en el marco de la coyuntura actual, si bien su intención es permitir la recuperación de la empresa, no se estaría cumpliendo su finalidad al imponer barreras en la obtención de una eventual financiación.

De esta manera, al estipularse la reducción del pasivo de forma que se entienda como una condonación, sea tácita o expresa, a diferencia de la renuncia, no hallaría sentido en que contara con los mismos efectos negativos sobre la calificación del riesgo, teniendo en cuenta que, en la renuncia para perseguir el pago parcial del crédito, no se extingue la obligación como sí sucede en la esfera de la condonación. Por tal motivo y atendiendo a la filosofía incentivadora del Decreto para la financiación de las empresas en riesgo, es que se afirma que no tendría sentido que quien acuda a estos pactos se vea afectado de manera negativa en su historial crediticio, sin mencionar el aspecto socioeconómico que lo caracteriza.

En síntesis, habiendo incorporado los Pactos de Deuda Sostenible como uno de los mecanismos de reestructuración y realizado el comparativo entre las quitas de deudas sobre sus efectos cuando en los primeros versen también la intención de disminuir el monto que se adeuda, nos permite afirmar que, al asimilarse las quitas con las renuncias o con el pactum de non petendo y las estipulaciones reductoras en los Pactos de Deuda Sostenible con las condonaciones, los efectos contables variarán al momento de calificar el riesgo por la celebración de uno de estos negocios jurídicos. Lo anterior en tanto, como se señaló en su momento, mientras uno representa una excepción que se podrá interponer cuando se trate de hacer efectivo el pago de la totalidad del pasivo que se adeudaba, en el otro evento estamos frente a la extinción parcial del vínculo obligacional existente. Poniéndose el ejemplo del pago posterior a la celebración del negocio jurídico, pues, de pagarse la parte remitida en el supuesto de una condonación, se tomará como pago de lo no debido y se podrán tomar las acciones que permitan la reincorporación 
al patrimonio de quien efectuó erróneamente el pago. Por el contrario, de pagarse la suma renunciada, se asimilaría al pago de una obligación natural en razón de que no se entiende extinguida esa parcialidad de la obligación, sino que el acreedor aceptó prescindir del derecho para hacer exigible esa parte de la deuda, permitiendo que se conserve la suma pagada.

Es por lo anteriormente mencionado, junto con la promoción que hace el Decreto a los incentivos financieros, que no tendría sentido, dado el efecto extintivo de la obligación en la condonación, que se perjudique al deudor frente al acceso del crédito cuando se encuentra este inmerso en una situación que dificulta la realización de su actividad comercial.

\section{5. ¿SON LOS PACTOS DE DEUDA SOSTENIBLE UNA FIGURA NOVEDOSA PARA EL ORDENAMIENTO JURÍDICO COLOMBIANO?}

La pregunta que ahora nos ocupa abarcar será si los Pactos de Deuda Sostenible resultan ser una figura completamente novedosa o si, por el contrario, habiendo realizado en análisis previo y siendo reconocida la posibilidad de pactar la reducción del pasivo que se va a pagar, podrían considerarse como una quita de deuda. Para esto habría que observarse si los Pactos de Deuda Sostenible fueron usados con anterioridad en nuestro ordenamiento e igualmente hacer un ejercicio más vigoroso respecto a las diferencias que se encuentran entre ambas figuras.

Sobre su aspecto novedoso, para dar respuesta a esta pregunta, habrá de señalarse que los Pactos de Deuda Sostenible parecieran haberse mencionado previamente en la práctica de los reperfilamiento de las deudas con los bancos, pero al no comprenderse muy bien la figura no tuvo mucha acogida en nuestro ordenamiento. Dicho lo anterior, se entiende que no estamos en presencia de una figura completamente novedosa, sin embargo, sí es novedosa la intención de su regulación siendo incorporada dentro de los mecanismos que se esperan sean usados para solventar los problemas suscitados con ocasión a la situación actual.

Ahora bien, para distinguir ambas figuras lo primero que habría que señalar es que quién celebre un Pacto de Deuda Sostenible no contará con una negativa en el historial crediticio, quedando su estado de riesgo en la misma situación en la que se encontraba. Diferencia que resulta ostensible comparado a los resultados de este trabajo por cuanto difiere de las quitas en este sentido. Lo anterior en razón de que los instrumentos incorporados en el Decreto fueron contemplados bajo la idea de reactivar la economía contando con la posibilidad de acceder al sistema crediticio durante la extensión de la crisis y luego de haberse superado esta.

Así es como el contexto socioeconómico cobra importancia en la incorporación de esta figura puesto que estamos hablando de las herramientas 
que el Gobierno Nacional vio con una especial importancia y con unas características particulares que permitirán soslayar la repercusión de estas sobre las empresas.

Otro punto en el cual se difiere de las quitas versa sobre la cantidad de acreedores que según el Decreto 560 de 2020 deben aprobar los pactos. Su artículo 4 señala que cuando se trate de Pactos de Deuda Sostenible estos deben ser aprobados por el $60 \%$ de los acreedores financieros, mientras que en la ley 1116 del 2006 en su artículo 33 se establece en su numeral primero, que las quitas requieren del $60 \%$ de la aprobación, pero esta vez respecto de un numero plural de acreedores no cualificados. El artículo 33 reza en sus numerales primero y segundo: "1. Sean aprobadas con el voto favorable de un numero plural de acreedores que equivalga a no menos del sesenta por ciento (60\%) de votos admisibles de los acreedores externos, de la clase cuyas acreencias serán afectadas y sin participación del voto de los acreedores internos" 23 .

Sin embargo, en el numeral 2 de este artículo se podría entender que estas quitas igual se pueden llegar a celebrar con el conocimiento individual y expreso de determinado acreedor, cuando dice, "2. Cuenten con el consentimiento individual y expreso del respectivo acreedor, en el caso de no contar con la mayoría prevista en el numeral anterior ${ }^{\prime 24}$. Punto en el que difieren con los Pactos de Deuda Sostenible en razón de que el Decreto no pareciera traer esa posibilidad consagrada.

Sobre lo anterior también habrá que mencionar que, mientras que las quitas llevan un recorrido en nuestra legislación, los Pactos de Deuda Sostenible son incorporados por un Decreto legislativo por lo que entendemos está llamado a tener vigencia por un período de tiempo específico y transitorio. Por eso reconocer su utilidad detalladamente resulta importante, porque esta podría significar su implementación definitiva en el ordenamiento jurídico colombiano en un futuro.

De acuerdo con lo anterior son varias las diferencias plausibles encontradas entre estas dos figuras, las cuales enumeramos a continuación y que hacen referencia a: 5.1 Los efectos sobre el historial crediticio 5.2 el tipo de acreedores que aprueban los pactos; 5.3 la restricción de pactarse con un acreedor sin la aprobación de los demás, 5.4 el contexto social y económico en el que se incorpora, 5.5 su carácter transitorio.

\subsection{LOS EFECTOS SOBRE EL HISTORIAL CREDITICIO}

Como se mencionó en su momento los créditos resultan ser piezas fundamentales para la superación de la situación de insolvencia en la que se pueda 
encontrar cualquier empresa. Por esta razón, el historial crediticio y su calificación de riesgo son elementos que cobran relevancia principalmente en estos momentos de crisis por lo que se pensaría que las entidades financieras serán más minuciosas en el examen que realicen antes de otorgar un crédito a quien lo solicite.

Es aquí donde se evidencia una ventaja en el uso de los Pactos de Deuda Sostenible frente a los demás mecanismos de reestructuración de créditos, recordando que, el Gobierno Nacional implementó esta herramienta en el Decreto esperando que prestaran mayor utilidad y eficacia en relación con las anteriores a la hora de iniciarse un proceso de reorganización.

Resultaría ilógico creer entonces que esta figura no tiene un salvamento o no representa una excepción a esta regla sobre los efectos negativos que podría conllevar la celebración de un acuerdo de esta índole sobre quienes se encuentren inmersos en un proceso de reorganización. Que es igualmente a lo que se apuntaba cuando se habló sobre los estímulos financieros que se esperan recibir de las entidades frente a una situación de insolvencia y la preferencia que se les concede a los créditos al ser tratados como gastos administración luego de ser concedidos con posterioridad al inicio del proceso.

Así lo pensó la Superintendencia Financiera de Colombia al incorporar en su Circular Externa 022 del 2020 las "Instrucciones para la definición del Programa de Acompañamiento a Deudores, e incorporación de medidas prudenciales complementarias en materia de riesgo de crédito" ${ }^{25}$. Puesto que, dentro de estas indicaciones se hace mención sobre los efectos contables que tendrán que soportar quienes celebren un mecanismo de reestructuración en estos momentos.

La primera instrucción que da la circular permite entender que, quienes acudan a la reestructuración del crédito con ocasión a la situación suscitada por la Covid-19, podrán conservar su última calificación, así lo establece cuando reza, "la calificación al momento de la redefinición podrá corresponder a la última calificación de riesgo del deudor. Sin embargo, ésta deberá ser revisada y actualizada a partir del proceso de calificación de noviembre atendiendo las instrucciones del Capítulo II de la Circular Básica Contable y Financiera-CBCF ${ }^{\prime 26}$. Esto quiere decir que no se afectará a quienes mantenían un historial sin calificaciones negativas, ni empeorará el historial de quien ya venía presentando dificultades para hacer efectivos los pagos que se adeudaban.

Habrá de señalarse igualmente que, la Circular Externa 026 del 2017 la Superintendencia Financiera de Colombia deja claro que la reestructuración de los créditos aumenta el riesgo crediticio de las empresas que a aquellas acudan y que entre más reestructuraciones se realicen mayor será el riesgo

25 Superintendencia de Industria y Comercio de Colombia. Circular Externa n. 022 de 2020.

26 Ibidem. 
de no poder pagar la obligación dentro de su calificación. Por esta razón, comprendiendo que antes de la crisis los mecanismos de reestructuración podían afectar la calificación del crédito frente a una entidad financiera, su celebración en la actualidad dejará su historial sin alteraciones.

Reafirmando la idea que trata la Circular Externa 022 que trata la instrucción primera, la instrucción octava nos indica que "con el fin de facilitar la implementación del programa señalado en la instrucción primera de la presente Circular, los créditos que sean objeto de redefinición o aplicación de las medidas en el marco del programa no serán considerados como modificados ni reestructurados. Sin embargo, aquellos créditos que al momento de la aplicación de las medidas adoptadas en el marco del programa presentaban tal condición, la mantendrán siguiendo las instrucciones previstas en el Capítulo II de la $C B C F^{\prime 27}$. Lo cual establece que para estos efectos no se entenderán los mecanismos de reestructuración como una reestructuración propiamente, pero en el sentido de que es por su celebración en la actualidad, sin embargo, de forma subsiguiente se expresa que de haberse celebrado este tipo de negocios jurídicos con anterioridad seguirá contando con su categoría y se le seguirán aplicando las regulaciones anteriores.

Adicionalmente, respecto de la calificación que se debía hacer a inicios de este año también la Circular Externa hace mención sobre su tratamiento cuando señala que, "el proceso de evaluación y calificación de la cartera de créditos de que trata el numeral 2.2.3.2 del Capítulo II de la CBCF correspondiente al mes de mayo de 2020 no será obligatorio. En todo caso se deberá cumplir con el proceso de calificación de todos los deudores en el mes de noviembre. Para estos efectos las entidades deberán considerar entre los parámetros de evaluación, las perspectivas de reactivación de la actividad económica de los deudores" 28 . Siendo así como no establece el requisito de la calificación del comportamiento frente al pago del crédito para el mes de mayo y como queda establece que en noviembre se deberá regresar a las instrucciones dadas en las circulares previas.

La Circular Externa 022 del 2020 da entonces la posibilidad mantener el historial crediticio frente a la redefinición de una deuda, sin embargo, su instrucción primera señala que se espera que en noviembre se vuelvan a tomar las medidas que se venían aplicando anteriormente en la calificación de los créditos. Entonces, se entiende que la instrucción otorga una especie de plazo de gracia en la cual se tiene la expectativa que para finales de año ya se normalicen las relaciones crediticias entre acreedores y deudores y así aplicar la regulación anterior. Sin embargo, esta expectativa que se tiene no parece tan posible, sobre todo cuando el proceso de reapertura gradual de los sectores económicos no ha avanzado tanto para permitir el buen desarrollo de la actividad comercial de muchas empresas. Es por esto que los Pactos de Deuda Sostenible y la condonación que en estos se pueda realizar siguen 
siendo un mecanismo bastante atractivo en nuestro ordenamiento suponiendo que estos podrán en principio ser aplicados hasta casi dos años más por la vigencia del Decreto 560 de 2020, sin contar con la posibilidad de que se perpetúen en nuestra legislación.

En síntesis, es así como el no calificar negativamente el historial crediticio de quien acuda a la celebración de Pactos de Deuda Sostenible representará un mayor beneficio ante la crisis en que nos encontramos incluso luego del período de gracia que establece la Circular Externa 022 del 2020. Igualmente se señala que, de no entenderse de esta manera iría en contravía con la misma esencia que promueve el Decreto dado que su espíritu refleja la importancia de los estímulos financieros, toda vez que se les da un inmenso valor a las entidades financieras como el actor principal de superación de la crisis. Lo anterior se observa en tanto que el Decreto busca asegurar o establecer una preferencia en el pago a estas entidades, sobre todo a quienes otorguen créditos después del inicio del proceso entendiéndolos como gastos de administración.

\subsection{ReSPECTO DE LOS ACREEDORES QUE APRUEBAN EL PACTO}

Como ya se dijo, frente a los acreedores necesarios para aprobar estos pactos vemos que, aunque el porcentaje de los acreedores se establece en un $60 \%$ para ambos, varía en la cualificación de estos. Por un lado, en las quitas de deudas se menciona que serán los acreedores externos vinculados al proceso de reorganización quienes podrán votar cuando se trate de una quita celebrada de forma conjunta. Mientras que, de tratarse de la celebración de un pacto de deuda sostenible, este requerirá de la aceptación, pero en esta oportunidad de los acreedores financieros.

Luego de haber resaltado las diferencias entre los tipos de acreedores necesarios para la aprobación de una u otra figura, es aquí donde se observa el espíritu proacreedor que apropia el Decreto. Esto se traduce en la intención de proteger y asegurar el pago de estos acreedores financieros por cuanto son el eje central de todo proceso de insolvencia, por cuanto tienen una evidente importancia en estos momentos de crisis para la conservación de la empresa entendiéndola como una institución generadora de trabajo y sustento para las familias colombianas.

El valor que representan las entidades financieras, no solo se prevé en el Decreto y su espíritu, sino que también se evidencia en los aportes económicos que el mismo gobierno ha desembolsado a los bancos en el transcurso de la crisis. Asimismo, el Decreto funciona como una reglamentación que pretenda el menor menoscabo para estas instituciones, teniendo en cuenta que es realmente por su importancia que se procura brindarles cierta seguridad para que sigan desempeñando ese papel y la economía no recaiga más de lo proyectado. 
El Decreto, al hacer expresa mención de que los Pactos de Deuda Sostenible necesitan de una mayoría cualificada para poder ser incorporados en un proceso de reorganización, evidencia claramente que el legislador no tenía la intención de asimilarlos a una quita. Por el contrario, les da prioridad a una clase de acreedores que podrían hacer uso de este mecanismo y que, como se ha mencionado, son parte importante en el proceso de recuperación de una empresa. De esta manera se concluye que las quitas apuntan a solventar un problema con actores diferentes a los que en principio se idearon para los Pactos de Deuda Sostenible, ya que este último se pensó para aquellos acreedores que representan un papel especial en la economía a lo largo de esta crisis.

\subsection{LA RESTRICCIÓN DE PACTARSE CON UN ACREEDOR SIN LA APROBACIÓN DE LOS DEMÁS}

Frente a este punto solo habrá que decir que esta diferencia hace a alusión a lo que encontramos consagrado dentro del numeral 2 del artículo 33 por cuanto pareciera permitir la celebración de quitas de deudas cuando se trate de un acreedor en específico y de una manera particular e independiente.

Es una característica relevante y que puede representar un beneficio cuando se trata de una serie de acreedores sobre todo de diferentes clases, pero al encontrarnos en los Pactos de Deuda Sostenible frente a acreedores calificados como son los financieros no encontramos contemplada la misma posibilidad.

Esto nos remite únicamente a entender que el deudor de una acreencia financiera cuando se encuentre en un proceso de reorganización podrá únicamente convenir estos pactos hasta el punto de que cuente con la aceptación prevista en el artículo 4 del Decreto 560 de 2020 para su incorporación dentro de los acuerdos de reorganización a los que llegue la empresa con sus respectivos acreedores.

No obstante, como ya se estudió, cuando se vaya a celebrar una quita con un acreedor de forma individual, esta se deberá incorporar como una cláusula dentro del acuerdo de reorganización. Nada evita que más adelante se desarrollen investigaciones que permitan la inclusión de acuerdos privados que consagren un pacto de deuda sostenible de manera individual dentro de los procesos de reorganización independientemente a la aceptación de los otros acreedores de su misma categoría.

\subsection{El CONTEXTO SOCIAL Y ECONÓMICO EN EL QUE Se incorporan los Pactos de Deuda Sostenible}

El contexto social es una diferencia evidente que se traduce en la intención del gobierno con la incorporación de esta figura dentro del Decreto. Es claro 
que ambas figuras están contempladas con la intención de coadyuvar en la recuperación de la empresa de cara a una situación de insolvencia. Pero, mientras una se daba en la práctica en circunstancias normales, la otra fue establecida para representar una herramienta aún más fuerte o con mayores beneficios para quien se enfrente a un proceso de reorganización de cara a la actual coyuntura, dado que ya representa en sí misma una dificultad mayor.

Esta parte es importante para señalar que, aunque por la urgencia que representó expedir esta normativa frente a la situación que atraviesa el país también aconseja que esta herramienta se debe ver con esa intención de representar una mayor utilidad en comparación a los otros mecanismos con los que se contaba antes de la crisis. Lo cual permite entender que si se hacen los análisis respectivos como los efectos de los créditos sobre quienes acudan a los Pactos de Deuda Sostenible se debe entender que surtirán efectos en beneficio del insolvente.

\subsection{El Carácter transitorio de los Pactos de Deuda Sostenible}

Son varias las figuras con las que ha contado el ordenamiento jurídico cuando de procesos de insolvencia se habla, pero como se mencionó anteriormente y dada la situación de emergencia se ve la necesidad de la incorporación de estrategias diferentes. Es así como los nuevos mecanismos encuentran un carácter transitorio que desde el mismo título se evidencia al mencionar que por medio del Decreto 560 se "adoptan medidas transitorias especiales en materia de procesos de insolvencia en el marco del Estado de Emergencia, Social y Ecológica", así, la necesidad de herramientas con un carácter especial ingresa a la normatividad en insolvencia para hacer frente a eventos diferentes con necesidades particulares.

Sin embargo, aún queda abierta la posibilidad, como se ha venido mencionando a lo largo del artículo, sobre la permanencia de las figuras contenidas en el Decreto. Esto dependerá mayormente de la utilidad que presten dichas instituciones en la recuperación empresarial, quedando en manos de las investigaciones que se presenten con posterioridad a la publicación de este artículo, la realización de un análisis de fondo respecto a la incidencia que se haya evidenciado sobre la figura en la conservación de la empresa y así poder preservarla en nuestra legislación.

\section{COROLARIO Y PRECISIONES FINALES SOBRE LOS PACTOS DE DEUDA SOSTENIBLE}

Una vez realizado el examen correspondiente a las características que identifican la figura de los Pactos de Deuda Sostenible podemos decir entonces que nos encontramos frente a una figura contractual que permite la modificación 
de las condiciones inicialmente estipuladas para el cumplimiento de una obligación en el marco de una situación de insolvencia.

Dicha figura se asimila a un mecanismo de reestructuración de crédito bajo la descripción que da la Superintendencia Financiera de Colombia de los mismos ya que esta señala que, "se entenderá como crédito o contrato reestructurado aquel respecto del cual se ba celebrado un negocio jurídico de cualquier clase que tenga como objeto o efecto modificar cualquiera de las condiciones originalmente pactadas, en beneficio del deudor ${ }^{\prime 29}$. Por consiguiente se afirma que cuando se hace mención a los Pactos de Deuda Sostenible también se estará haciendo alusión a un mecanismo de esta índole, teniendo en cuenta lo igualmente establecido por el Decreto 560 del 2020 al señalar que la finalidad de esta figura versa en la reactivación de la empresa mediante el reperfilamiento o la reestructuración de las obligaciones existentes.

Dicho lo anterior habrá de señalarse que la figura fue inicialmente concebida para que dentro de una situación donde predomina la crisis empresarial obre como una herramienta de auxilio que permita, de forma conjunta con los acreedores, acordar nuevas vías de pago en donde se acople a la realidad por la que atraviesa el deudor sin que medie un cronograma de pagos. Pero al reconocerse como un negocio jurídico, en coherencia de los principios contractuales mencionados, este podrá ser igualmente incluido dentro de un acuerdo privado que sea celebrado por las partes y posteriormente sea agregado al acuerdo de reorganización para ser validado por el juez competente. Permitiendo así su utilización por fuera de los parámetros consagrados en el Decreto, los cuales la advierten como una figura con miras principalmente a favorecer una clase de acreedores individualmente considerada.

Ahora bien, la novedad de la figura depende claramente de la finalidad de la misma. Como se venía diciendo la figura fue consagrada como una herramienta que permite el reescalonamiento de la deuda para que se vayan absolviendo las obligaciones pendientes que más dificultan la recuperación de la empresa mientras continúe con su funcionamiento. El reescalonamiento se hace en función del tiempo permitiendo al deudor acomodarse a la capacidad de pago que presente respecto a su mejoría con la aprobación de los acreedores. Por tal motivo no parece ser una figura innovadora en relación con las otras ya existentes en el ordenamiento en tanto que permiten postergar el cumplimiento de la obligación. Sin embargo, el no considerar un cronograma de pagos para la atención del pasivo, sí resulta ser novedoso para nuestro ordenamiento jurídico.

Frente a las ventajas que se podrían observar con el uso de los Pactos de Deuda Sostenible, adicional a la permisión de no considerar un cronograma

29 Superintendencia Financiera de Colombia. Circular Básica Contable y Financiera n. ${ }^{\circ}$ 100 de 1995 
de pagos, está la no afectación del historial crediticio. Esta ventaja resulta ser la más relevante dado que busca mantener la facilidad en la obtención del crédito para el funcionamiento de la empresa, teniendo en cuenta las consideraciones hechas por la Circular Externa 022 del 2020 expedida por la Superintendencia Financiera de Colombia que incluye este beneficio para los demás mecanismos hasta noviembre del presente año. Sobre las otras instituciones que consagra el Decreto, a diferencia de la capitalización y la descarga de pasivos, los Pactos de Deuda Sostenible son, in nostra sententia, mecanismos de reestructuración de crédito lo que permite encajarlo dentro de las directrices que han proferido las diferentes entidades para su tratamiento, quedando así, exentos de los beneficios contables y demás tratamientos.

Son los argumentos presentados alrededor del desarrollo de este artículo los que ahora dejan la incógnita sobre su permanencia en nuestro ordenamiento jurídico. Claro está que será deber de futuras investigaciones ocuparse de examinar el resultado que dejó la inclusión de la figura en nuestra legislación una vez superada las circunstancias que hoy nos constriñen en relación a la Covid-19.

\section{BIBLIOGRAFIA}

Superintendencia de Industria y Comercio de Colombia. Circular Externa n. ${ }^{\circ} 016$ de 2 julio de 2019.

Valencia Zea Arturo, Derecho Civil de las Obligaciones, t. III, Bogotá, Edit. Temis, 1998, p. 304.

Hinestrosa, Fernando. 2007, Tratado de las Obligaciones, Concepto, Estructura, Vicisitudes, Bogotá D.C. Universidad Externado de Colombia.

Hinestrosa, Fernando. 2007, Tratado de las Obligaciones, Concepto, Estructura, Vicisitudes, Bogotá D.C. Universidad Externado de Colombia.

¿Qué son las quitas de deuda?, BBVA. Actualización 13 de Junio de 2018. https:// www.bbva.com/es/que-son-las-quitas-de-deudas/

Ley 1116 de 2006, artículo 33.

Superintendencia Financiera de Colombia. Circular Básica Contable y Financiera n. ${ }^{\circ} 100$ de 1995.

Valencia, Arturo, 1998. Derecho Civil, Parte General y Personas. Tomo I, Bogotá, Edit. Temis, pág. 452.

Decreto 560 de 2020, artículo 4. 
La Remisión, Facultad de Derecho Universidad de los Andes. Última Modificación 13 mayo de 2020. https://hipertexto-obligaciones.uniandes.edu.co/doku. php?id=remision

Qué debe saber si va a reestructurar su deuda. El ECONOMISTA. 24 de junio de 2018. https://www.eleconomista.com.mx/finanzaspersonales/Que-debe-sabersi-va-a-reestructurar-su-deuda-20180624-0059.html

Consolidación, reestructuración y quita; estas son las tres formas que los bancos pueden ofrecerte para negociar tu deuda, te decimos las diferencias. Business Insider Mexico. 3 de junio de 2020. https://businessinsider.mx/consolidacionreestructuracion-y-quita-tres-formas-que-los-bancos-pueden-ofrecerte-paranegociar-deudas/

Decreto 560 de 2020, artículo 5.

Superintendencia de Industria y Comercio de Colombia. Circular Externa n. ${ }^{\circ} 022$ de 2020.

Quita de la Deuda. Economipedia. 7 de octubre de 2015 https:/economipedia.com/ definiciones/quita-de-la-deuda.html

Superintendencia de Industria y Comercio de Colombia. Circular Externa n. ${ }^{\circ} 026$ de septiembre de 2017.

Superintendencia de Sociedades de Colombia. Concepto 2001057827-1 del 25 de octubre de 2001.

¿Qué Es Una Quita De Deuda? Andbank. 1 de abril de 2013.

Superintendencia de Sociedades de Colombia. Oficio 220-246341 del 15 de diciembre de 2016.

¿Cómo se inicia un proceso de insolvencia? Superintendencia de Sociedades. https:// www.supersociedades.gov.co/Servicio_Ciudadano/Paginas/preguntas_frecuentes/proceso_insolvencia.aspx\#: :text=proceso $\% 20 \mathrm{de} \% 20$ insolvencia\&text $=\%$ E2 \%80\%8B\%C2\%BFC\%C3\%B3mo\%20se\%20inicia\%20un\%20proceso\%20de $\% 20$ insolvencia $\% 3$ F\&text=El\%20proceso $\% 20$ de $\% 2$ reorganizaci\%C3\%B3n\%20 pretende,administrativa $\% 2$ C $\% 20 \mathrm{de} \% 20$ activos $\% 200 \% 20$ pasivos.

El Club de Paris: Una visión de largo plazo. Boletín Económico-Banco de España n. ${ }^{\circ}$ 109-110. 2012. https://core.ac.uk/download/pdf/322622188.pdf 